\title{
A Comparison of Full Arch Trueness and Precision of 9 Intraoral Digital Scanners and 4 Lab Digital Scanners
}

\author{
Adam Nulty ${ }^{1 *}$ \\ 1 University of Leeds, Woodhouse Lane, Leeds, LS2 9JT; dnabn@leeds.ac.uk \\ * Correspondence: dnabn@leeds.ac.uk
}

\begin{abstract}
Background: The purpose of this study is to evaluate the full arch scan accuracy (precision and trueness) of nine digital intra-oral scanners and four lab scanners. Previous studies have compared the accuracy of some intra-oral scanners, but as this is a field of quickly developing technologies, a more up-to-date study was needed to assess the capabilities of currently available models.; (2) Methods: The present in vitro study compared nine different intraoral scanners (Omnicam 4.6; Omnicam 5.1; Primescan; CS 3600; Trios 3; Trios 4; Runyes; 500 and DL206) as well as four lab light scanners (Einscan SE; 300e; E2 and Ineos X5) to investigate the accuracy of each scanner by examining the overall trueness and precision. Ten aligned and cut scans from each of the intra-oral and lab scanners in the in vitro study were brought into CloudCompare. A comparison was made with the master STL using the CloudCompare 3D analysis best-fit algorithm. The results were recorded along with individual standard deviation and a colorimetric map of the deviation across the surface of the STL mesh; a comparison was made to the master STL, quantified at specific points. ; (3) Results: In the present study, the Primescan had the best overall trueness $(17.3 \pm 4.9)$. Followed by (in order of increasing deviation) the Trios 4 (20.8 \pm 6.2$)$, i500 (25.2 \pm 7.3$),$ CS3600 (26.9 \pm 15.9 ), Trios $3(27.7 \pm 6.8)$, Runyes (47.2 \pm 5.4$)$, Omnicam 5.1 (55.1 \pm 9.5$)$, Omnicam 4.6 (57.5 \pm 3.2 ) and Launca DL206 (58.5 \pm 22.0$)$. Regarding the lab light scanners, the Ineos X5 had the best overall trueness with $(0.0 \pm 1.9)$. Followed by (in order of increasing deviation) the 3Shape E2 (3.6 \pm 2.2$)$, Up3D 300E (12.8 $\pm 2.7)$, and Einscan SE (14.9 \pm 9.5); (4) Conclusions: This study confirms that all current generations of intra-oral digital scanners can capture a reliable, reproducible full arch scan in dentate patients. Out of the intra-oral scanners tested, no scanner produced results significantly similar in trueness to the Ineos X5. However, the Primescan was the only one to be statistically of a similar level of trueness to the 3Shape E2 lab scanner. All scanners in the study had mean trueness of under 60micron deviation. While this study can compare the scanning accuracy of this sample in a dentate arch, the scanning of a fully edentulous arch is more challenging. The accuracy of these scanners in edentulous cases should be examined in further studies.
\end{abstract}

Keywords: Intraoral scanners, digital dentistry, trueness, precision, lab scanners

\section{Introduction}

The emergence and use of intra-oral scanners in dental clinics has provided a better experience for the patient and an easier way of creating an impression model in a more predictable and repeatable way to alleviate problems or complications encountered in a conventional workflow using traditional methods with a tray-based impression.[1] When the digital intra-oral scanners were introduced in the 1980s, the fully digital workflow became a reality.

Several recent technical improvements have made the intra-oral digital scanner a central part of modern dental surgery, enabling same-day dentistry, reducing the need for conventional impressions, or even replacing them entirely. Many clinicians are now starting to use a digital scanner, and there is a number of well-performing scanners on the market. 
There are many clinical advantages compared to conventional impression taking. Namely, speed, patient comfort, efficacy, and several new ways dentists can predictably work once the intra-oral situation is digitised. Also, a significant factor is that the use of a digital scanner can reduce costs in the long run.[2,3,4]

An alternative way of digitising the intra-oral environment is through the capture of either an impression or casted model in a lab scanner, but this study will focus on the use of direct intra-oral scanners and compare their relative accuracy to a base level lab scanner.

While there have been several previous studies comparing the accuracy of intra-oral scanners, there are no currently published studies that compare the scanners available in 2020, namely those in the present study. $[5,6,7,8,9]$ It has been suggested that using a digital intra-oral scanner for a full arch scan is less acceptable as the longer scan distance may introduce a possible error.[10]

The technology used in scanners varies, and therefore the ease of use, efficacy, and accuracy in terms of trueness and precision may vary. The scanner will measure a number of intra-oral readings and create a three-dimensional image using a mathematical algorithm. Due to the limited field of view of an intra-oral scanner, the single point cloud map generated with each scan frame cannot cover all of the teeth' surfaces. Thus the scanner software overlaps these frames with subsequently captured frames to create a unified $3 \mathrm{~d}$ mesh representing the full arch.[11] Depending on the manufacturer and the scanning technology employed, various algorithms and stitching methods combine these individual images. However, these methods inherently contain a degree of error that can accumulate across the dental arch when a full arch scan is performed.[12,13,14] The outcome of the digital models is based on how reproducible, and accurate the scan is. The varying degree to which the scanners perform this stitching function will mean that the choice of the scanner may influence the overall accuracy of the resulting scan.[15,16] This study has focused on the Precision and Trueness of nine modern intra-oral digital scanners and four digital lab scanners. Accuracy consists of trueness and precision (ISO 5725-1).[17] Trueness is, by definition, an indication of how similar a measurement is to a known measured value.[18] In the present study, trueness describes the deviation of the measurements in the data set compared to the actual dimensions of the scanned object. Therefore, high trueness indicates that the scanner delivers a result that is very close to the actual dimensions of the object being scanned.[18] Precision indicates how reproducible similar repeated measurements are.[18] In the present study, precision describes how close each measurement in the data set is to the other measurements taken by the same scanner. Therefore, higher precision means that a scanner is capable of taking consistently repeatable scans.

As the scan data obtained in a clinical situation is the basis of the planning and design, it is of great importance that the scan is recording an accurate reading in a reproducible way. Therefore, we have compared the Trueness and Precision to get a value of accuracy on scanning a master model for the leading scanners currently in use and two lab scanners for comparison.

The null hypothesis was that no differences would be found between the various scanners regarding accuracy and precision.

A secondary null hypothesis was that there would be no difference between the lab scanners and intra-oral scanners regarding accuracy and precision. 


\section{Materials and Methods}

\section{Study Model}

The present study used the International Digital Dental Academy[19] Calibration Model (Figure 1), which represents three different situations in the maxilla;

- A fully dentate arch.

- Four regular structures in the form of columns of known width and separation.

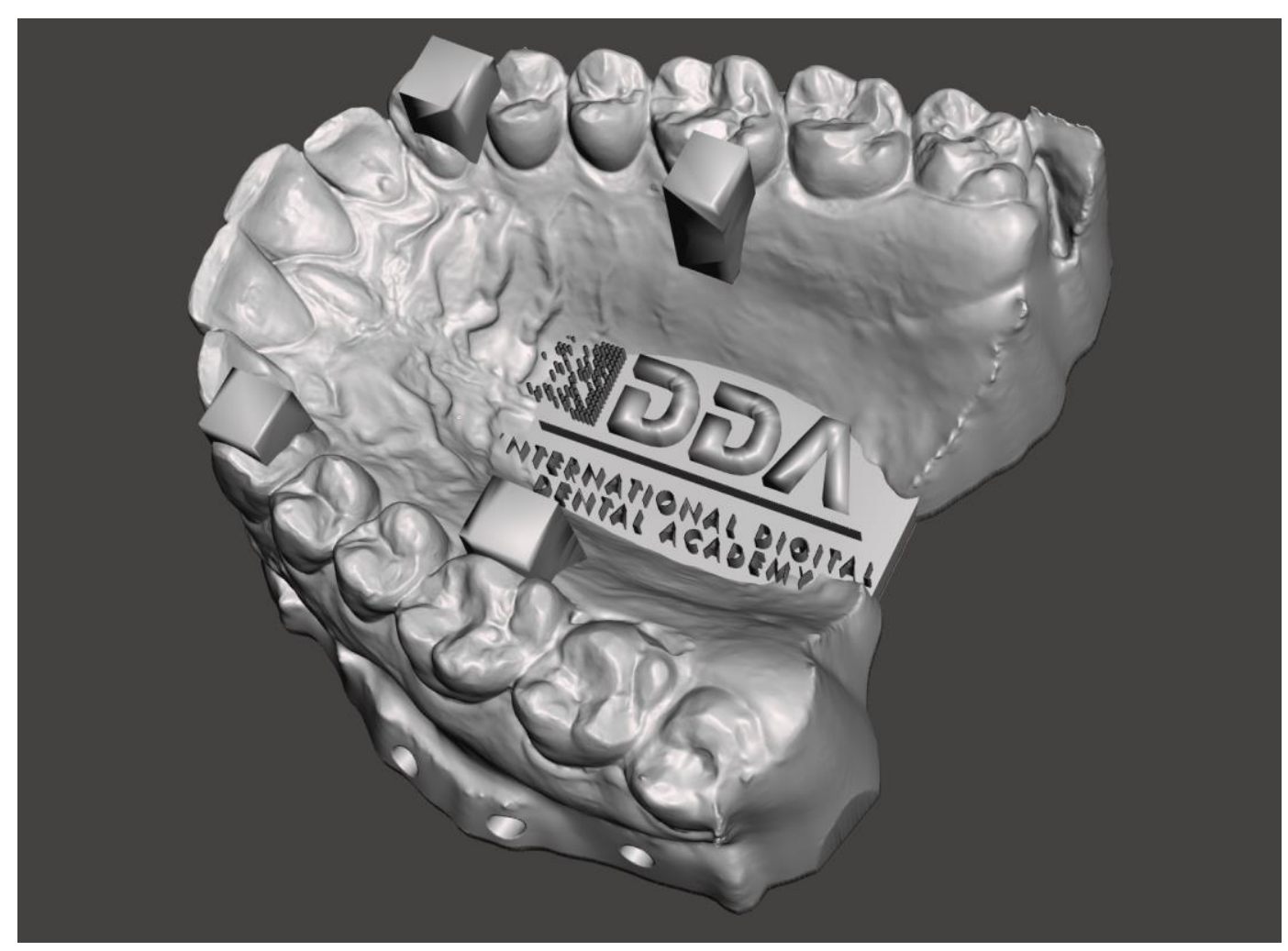

- A high degree of surface morphology.

Figure 1. The IDDA Calibration Model

This master model was printed using an Asiga Max UV and NextDent Model Resin at 50 micron layer height. This printer and resin combination was chosen for high precision and low reflectivity to facilitate the acquisition with the intraoral scanners used in the study.

\section{Scanners in the study}

The scanners used in the present in vitro study are summarised in Table 1. 
Table 1. The Digital Scanners Used In This Study

\begin{tabular}{|c|c|c|c|c|}
\hline Name & Manufcturer & Technology & STL Export & $\begin{array}{c}\text { PLY/OBJ Colour Ex- } \\
\text { port }\end{array}$ \\
\hline Omnicam 4.6 & $\begin{array}{l}\text { Dentsply-Sirona, } \\
\text { York, } \\
\text { Pennsylvania, USA }\end{array}$ & $\begin{array}{c}\text { Structured light -Op- } \\
\text { tical } \\
\text { triangulation and } \\
\text { confocal } \\
\text { microscopy }\end{array}$ & YES & $\mathrm{NO}$ \\
\hline Omnicam 5.1 & $\begin{array}{l}\text { Dentsply-Sirona, } \\
\text { York, } \\
\text { Pennsylvania, USA }\end{array}$ & $\begin{array}{c}\text { Structured light -Op- } \\
\text { tical } \\
\text { triangulation and } \\
\text { confocal } \\
\text { microscopy }\end{array}$ & YES & $\mathrm{NO}$ \\
\hline Primescan & $\begin{array}{c}\text { Dentsply-Sirona, } \\
\text { York, } \\
\text { Pennsylvania, USA }\end{array}$ & $\begin{array}{l}\text { Structured light - } \\
\text { Confocal } \\
\text { microscopy with } \\
\text { Smart Pixel sensor. }\end{array}$ & YES & $\mathrm{NO}$ \\
\hline CS3600 & $\begin{array}{c}\text { Carestream Dental, } \\
\text { Atlanta, Georgia, } \\
\text { USA }\end{array}$ & $\begin{array}{l}\text { Structured light-Ac- } \\
\text { tive } \\
\text { Speed 3D Video } \\
\text { TM }\end{array}$ & YES & YES \\
\hline Trios 3 & $\begin{array}{c}\text { 3-Shape, Copenha- } \\
\text { gen, } \\
\text { Denmark }\end{array}$ & $\begin{array}{l}\text { Structured light - } \\
\text { Confocal } \\
\text { microscopy and Ul- } \\
\text { trafast } \\
\text { Optical Scanning }\end{array}$ & YES & YES \\
\hline Trios 4 & $\begin{array}{c}\text { 3-Shape, Copenha- } \\
\text { gen, } \\
\text { Denmark }\end{array}$ & $\begin{array}{l}\text { Structured light - } \\
\text { Confocal } \\
\text { microscopy and Ul- } \\
\text { trafast } \\
\text { Optical Scanning }\end{array}$ & YES & YES \\
\hline Runyes & $\begin{array}{c}\text { Ningbo Runyes Med- } \\
\text { ical Instrument Co., } \\
\text { China }\end{array}$ & $\begin{array}{l}\text { Structured light-Ac- } \\
\text { tive } \\
\text { Speed 3D Video } \\
\text { TM }\end{array}$ & YES & YES \\
\hline Launca DL206 & $\begin{array}{c}\text { Guangdong Launca } \\
\text { Medical Device Tech- } \\
\text { nology Co., Ltd, } \\
\text { Dongguan, China }\end{array}$ & $\begin{array}{l}\text { Structured light-Ac- } \\
\text { tive } \\
\text { Speed 3D Video }\end{array}$ & YES & YES \\
\hline
\end{tabular}




\begin{tabular}{|c|c|c|c|c|}
\hline Name & Manufcturer & Technology & STL Export & $\begin{array}{l}\text { PLY/OBJ Colour Ex- } \\
\text { port }\end{array}$ \\
\hline I500 & $\begin{array}{l}\text { Medit, Seongbuk-gu, } \\
\text { Seoul, Korea }\end{array}$ & $\begin{array}{c}\text { Structured light -Op- } \\
\text { tical } \\
\text { triangulation and } \\
\text { confocal } \\
\text { microscopy }\end{array}$ & YES & YES \\
\hline Einscan SE & $\begin{array}{l}\text { Shining 3D, Hang- } \\
\text { zhou, Zhejiang, } \\
\text { China }\end{array}$ & $\begin{array}{l}\text { Optical Blue Struc- } \\
\text { tured Light }\end{array}$ & YES & $\mathrm{NO}$ \\
\hline UP3D 300E & $\begin{array}{c}\text { Shenzhen UP3D Tech } \\
\text { Co., Ltd., Shenzhen, } \\
\text { China }\end{array}$ & $\begin{array}{l}\text { Optical Blue Struc- } \\
\text { tured Light }\end{array}$ & YES & $\mathrm{NO}$ \\
\hline E2 & $\begin{array}{c}\text { 3-Shape, Copenha- } \\
\text { gen, } \\
\text { Denmark }\end{array}$ & $\begin{array}{l}\text { Optical Blue Struc- } \\
\text { tured Light }\end{array}$ & YES & $\mathrm{NO}$ \\
\hline Ineos X5 & $\begin{array}{l}\text { Dentsply-Sirona, } \\
\text { York, } \\
\text { Pennsylvania, USA }\end{array}$ & $\begin{array}{l}\text { Optical Blue Struc- } \\
\text { tured Light }\end{array}$ & YES & $\mathrm{NO}$ \\
\hline
\end{tabular}

\section{Design of the study}

The present in vitro study compared nine different intra-oral scanners (Omnicam with 4.6 Software, Omnicam with 5.1 Software and Primescan, Dentsply Sirona, York, Pennsylvania; CS 3600, Carestream Dental, Atlanta, Georgia USA; Trios 3 and Trios 4, 3Shape, Copenhagen, Denmark; Runyes Quickscan, Ningbo Runyes Medical Instrument Co., China, and i500, Medit, Seongbuk-gu, Seoul, KoreaSeongbuk-gu, Seoul, Korea; DL206, Guangdong Launca Medical Device Technology Co., Ltd, Dongguan, China.) as well as four lab light scanners (Einscan SE, Shining 3D, Hangzhou, Zhejiang, China; UP3D 300e, Shenzhen UP3D Tech Co., Ltd., Shenzhen, China; E2, 3Shape, Copenhagen, Denmark, and Ineos X5, Dentsply Sirona, York, Pennsylvania) to investigate the accuracy of each scanner by examining the overall trueness and precision.

The master model was acquired with each of the above scanners and compared with the Ineos X5 Lab Scanner. This lab scanner is accredited to be accurate within 2.1 microns (ISO 12836)[20]

A single operator, an expert in digital dentistry familiar in use and experienced with multiple manufacturers of scanners, then began to scan the master model using each of the scanners available, capturing ten scans in total for each scanner. To avoid operator fatigue, the sequence of scans was randomised with intervals between each scan.

In each scan, the method of scanning followed the International Digital Dental Academy Scan Training Model[19] (Figure 2): starting on the upper left most distal molar, continuing occlusally across the full arch, pivoting to the palatal side to capture the palatal surfaces, and then returning along the buccal surface, with a constant progression. 


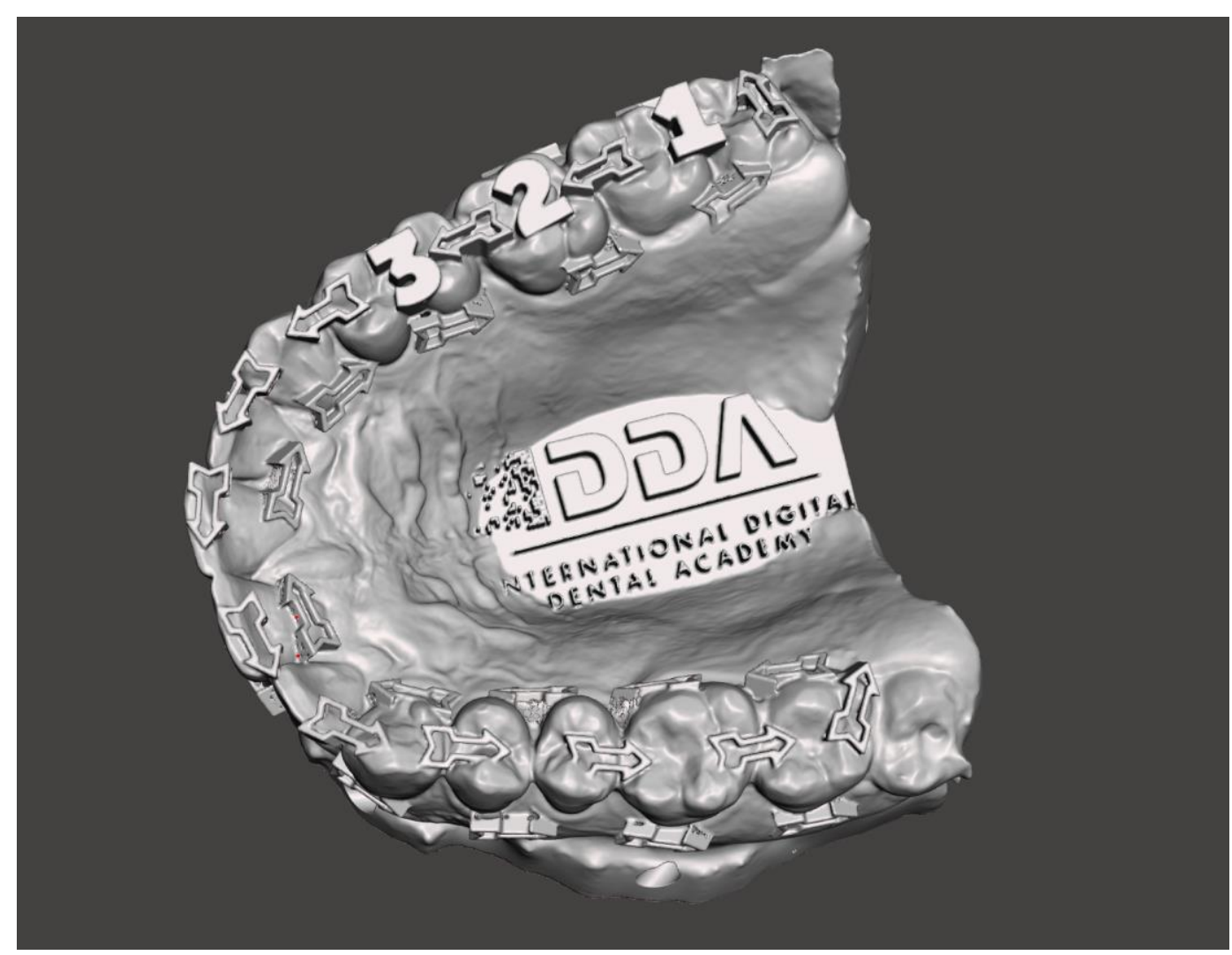

Figure 2. The IDDA Scan Method Training Model

This scanning method captures a little of the palatal and buccal surface when scanning the occlusal arc, capturing the areas of interest of each surface while maintaining a common framework for the meshes to align. The scans were exported as an STL format file using the manufacturer's proprietary and recommended conversion pathway.

The scans were then imported into Meshlab[21] (an open-source system for processing and editing 3D triangular meshes) and aligned.

This method was repeated with each of the intra-oral scanners and lab scanners in the study. Once all of the scans were aligned, the surface meshes were digitally cut using a template and exported to give ten resulting meshes for each scanner to be used to compare the trueness and precision evaluations.

\section{Evaluating Trueness}

For trueness, the master model scans using the Ineos X5 were used as a baseline measurement against the Original STL of the IDDA Calibration Model. Each of the ten aligned and cut scans from each of the scanners in the in vitro study was brought into CloudCompare (an open 3D point cloud and mesh processing and comparison software), where the scans were further aligned and calibrated using the fine alignment algorithm. Each data set was then compared with the master STL using the CloudCompare 3D analysis best-fit algorithm. Trueness was defined as the mean deviation value for the superimposition of each scan. The results were recorded along with the standard deviation for each scan. 


\section{D Deviation}

The CloudCompare software allows the generation of a colorimetric map of the deviation across the surface of the STL mesh as compared to the master STL, quantified at specific points. The colour map indicates deviation inward (blue) or outward (red), while green indicates minimal deviation. The same C2M colour deviation scale was employed to illustrate the minimum and maximum deviations for each comparison. The colour scale ranged from a maximum and minimum deviation of +200 (outward/red) and $-200 \mu \mathrm{m}$ (inward/blue).

\section{Evaluating Precision}

All possible pairwise comparisons were made using a one-way analysis of variance (ANOVA) for independent groups, with a Tukey significance level of 0.05 , of multiple comparisons using SPSS 26 by IBM.[22] Bartlett's test was used to test the homogeneity of variances. Precision was defined from the superimposition between the different scans made with the same intraoral scanner. Ten comparisons were available for each scanner, and the precision of each scanner was then expressed as a mean.

\section{Surface Detail Observational Comparison}

Finally, an illustration of the surface features was made by capturing the wireframe of the premolar/molar region incorporating the calibration column.

\section{Results}

Trueness and Precision results are summarised in Tables 2 and 3 and in Figures 3 and 4.

Table 2. Mean Trueness and Standard Deviation of Each Scanner in comparison to the Master Scan from the Ineos X5 in order of ascending mean deviation and the significance compared to the Ineos $\mathrm{X} 5$ results.

\begin{tabular}{|c|c|c|c|}
\hline Name & Mean ( $\mu \mathrm{m})$ & Std. Deviation ( $\mu \mathrm{m})$ & P Value \\
\hline Ineos X5 & 0.0 & 1.9 & 1.000 \\
\hline 3Shape E2 & 3.6 & 2.2 & 0.125 \\
\hline UP3D 300E & 12.8 & 2.7 & 0.029 \\
\hline Einscan SE & 14.9 & 9.5 & 0.004 \\
\hline Primescan & 17.3 & 4.9 & $<000.1$ \\
\hline Trios 4 & 20.8 & 6.2 & $<000.1$ \\
\hline Medit i500 & 25.2 & 7.3 & $<000.1$ \\
\hline CS3600 & 26.9 & 15.9 & $<000.1$ \\
\hline Trios 3 & 27.7 & 6.8 & $<000.1$ \\
\hline Runyes & 47.2 & 5.4 & $<000.1$ \\
\hline Omnicam 5.1 & 55.1 & 9.5 & $<000.1$ \\
\hline Omnicam 4.6 & 57.5 & 3.2 & $<000.1$ \\
\hline Launca DL206 & 58.5 & 22.0 & $<000.1$ \\
\hline
\end{tabular}




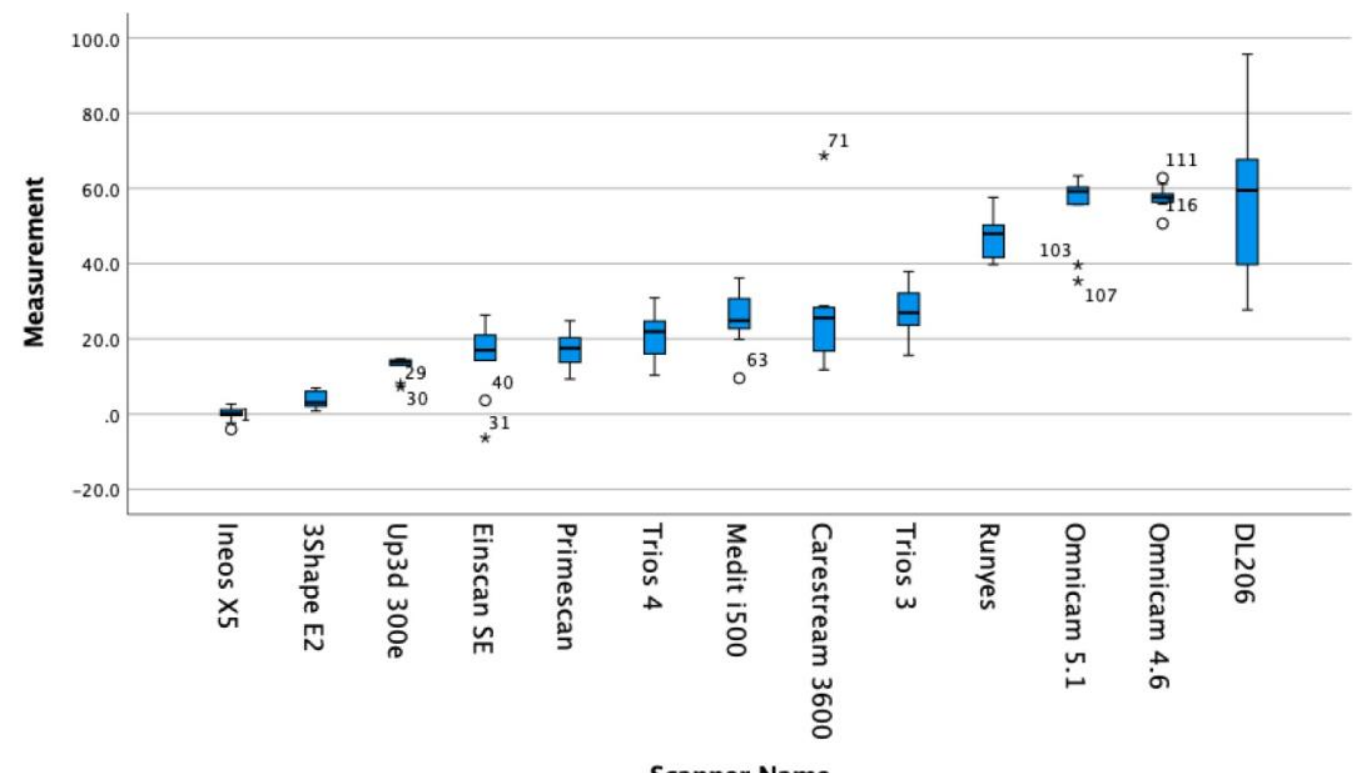

Scanner Name

Figure 3. Box Plot of Each Data Set for Each Scanner in the Present Study

Table 3. Tukey Homogenous Subsets of Compared Means (Subset for alpha = 0.05)

\begin{tabular}{|c|c|c|c|c|c|}
\hline Name & 1 & 2 & 3 & 4 & 5 \\
\hline Ineos X5 & 0.000 & & & & \\
\hline 3Shape E2 & 3.7 & 3.7 & & & \\
\hline UP3D 300E & 12.8 & 12.8 & 12.8 & & \\
\hline Einscan SE & & 15.0 & 15.0 & 15.0 & \\
\hline Primescan & & 17.3 & 17.3 & 17.3 & \\
\hline Trios 4 & & & 20.9 & 20.9 & \\
\hline Medit i500 & & & 25.2 & 25.2 & \\
\hline CS3600 & & & 26.9 & 26.9 & \\
\hline Trios 3 & & & & 27.7 & \\
\hline Runyes & & & & & 47.2 \\
\hline Omnicam 5.1 & & & & & 55.2 \\
\hline Omnicam 4.6 & & & & & 57.6 \\
\hline Launca DL206 & & & & & 58.5 \\
\hline
\end{tabular}




\begin{tabular}{cccccc}
\hline Name & $\mathbf{1}$ & $\mathbf{2}$ & $\mathbf{3}$ & $\mathbf{4}$ & $\mathbf{5}$ \\
\hline P Value (Sig) & 0.125 & 0.072 & 0.051 & 0.123 & 0.271 \\
\hline
\end{tabular}

Table 4. Anova Sig. Between groups.

\begin{tabular}{cccccc}
\hline \multicolumn{5}{c}{ Anova } & \\
\hline Measurement & Sum of Squares & Df & Mean Square & F & Sig. \\
\hline Between Groups & 28324.784639 & 8 & 3540.598080 & 29.235153 & 0.000 \\
\hline Within Groups & 9809.712588 & 81 & 121.107563 & \\
\hline Total & 38134.497226 & 89 & & \\
\hline
\end{tabular}

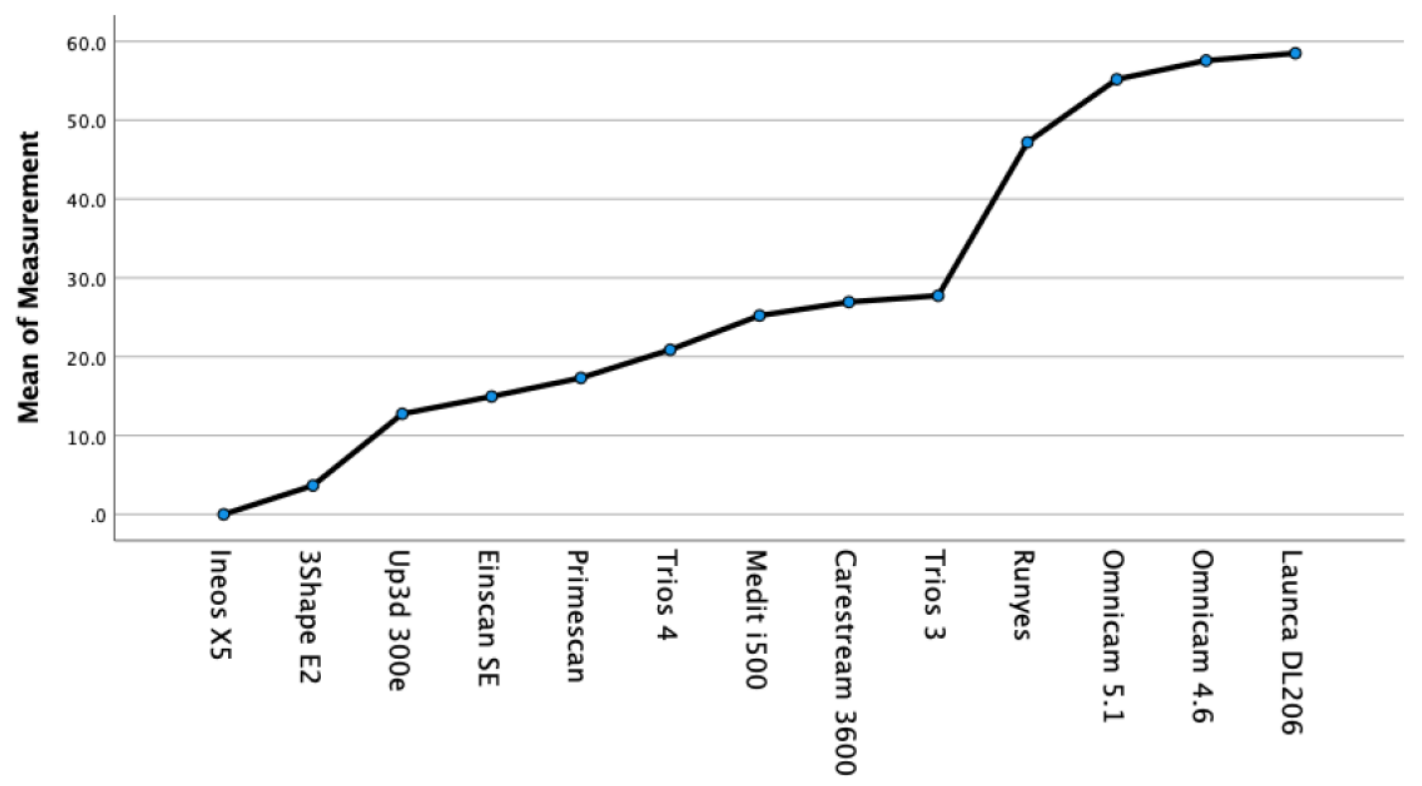

Scanner Name

Figure 4. Means Plot of Precision for each Scanner.

In the present study, the Primescan had the best overall trueness (17.3 \pm 4.9$)$. Followed by (in order of increasing deviation) the Trios 4 (20.8 \pm 6.2$)$, i500 (25.2 \pm 7.3$),$ CS3600 (26.9 \pm 
15.9), Trios 3 (27.7 \pm 6.8), Runyes (47.2 \pm 5.4$)$, Omnicam 5.1 (55.1 \pm 9.5$)$, Omnicam 4.6 (57.5 $\pm 3.2)$ and Launca DL206 (58.5 \pm 22.0$)$.

With regards to the lab light scanners, the Ineos X5 had the best overall trueness with $(0.0$ \pm 1.9 ). Followed by (in order of increasing deviation) the 3Shape E2 (3.6 \pm 2.2$)$, Up3D 300E $(12.8 \pm 2.7)$ and Einscan SE $(14.9 \pm 9.5)$

Figure 5. Colorimetric map of the deviation

The precision results are summarised in Table 3. In brief, the Ineos X5 was statistically more precise than all of the intra-oral scanners. The Primescan intra-oral scanner was the only intra-oral scanner statistically grouped in precision with desktop lab scanners E2 and 300E. Six of the intra-oral scanners, the Primescan, Trios 4, i500, 3600, and Trios 3, were statistically more precise than the Runyes, Omnicam, and DL206.

All intra-oral scanners present a mean error below 60 microns across a full arch comparison. Five current-generation scanners in the study (excluding the Runyes, Omnicam, and Launca) provide a mean error below 30 microns with a low deviation which confirms a 


\section{LAB SCANNERS}

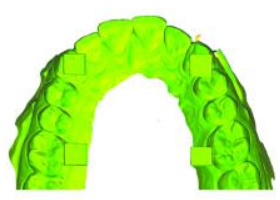

Ineos $\times 5$

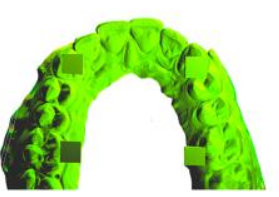

3Shape E2

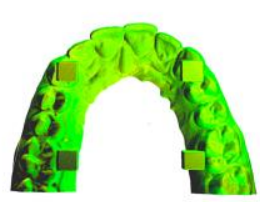

UP3D 300E

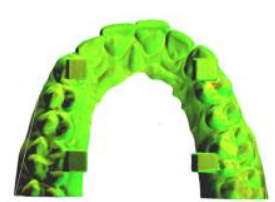

Shining Einscan SE

INTRAORAL SCANNERS

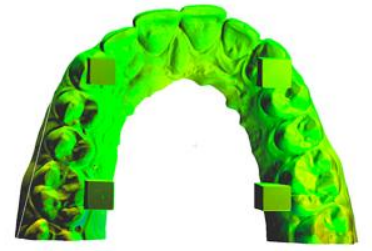

Primescan

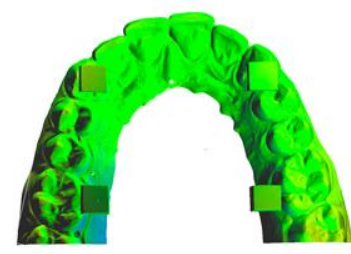

Medit 1500

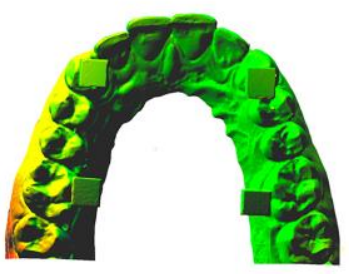

Omnicam 5.1

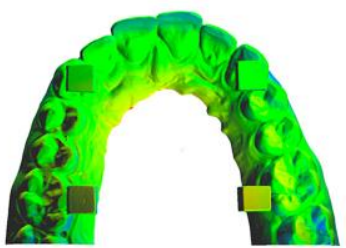

Trios 4

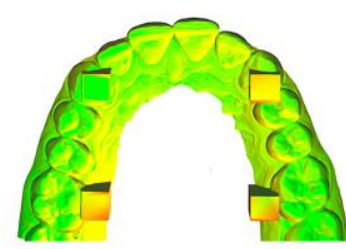

$\operatorname{cs} 3600$

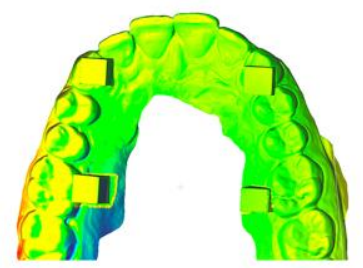

Omnicam 4.6

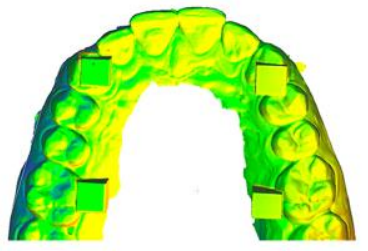

Runyes 3DS

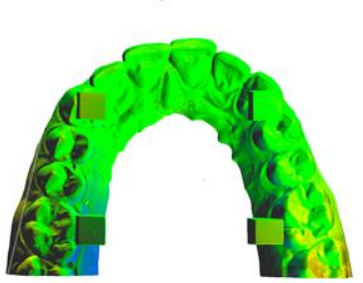

Trios 3

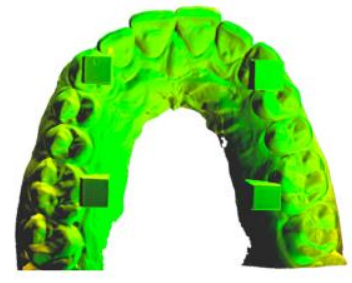

Launca DL206

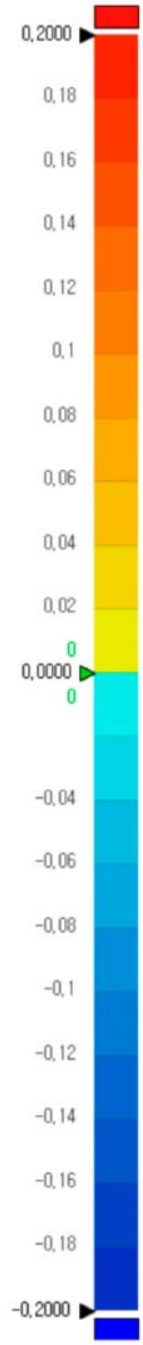

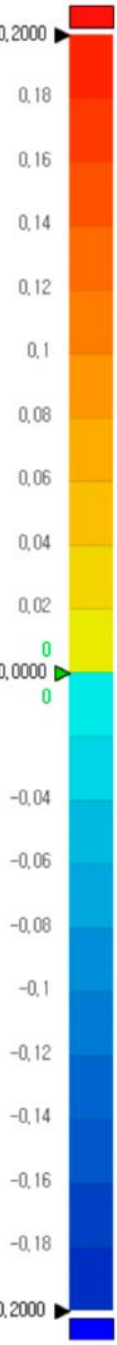

high level of reliability of the Primescan, Trios 3 and 4, i500 and CS3600. The oldest model of scanner, the Omnicam, was tested with two varieties, running software version 4.6 and version 5.1. The current 5.1 hardware and software is credited as having improved the accuracy of this scanner which has been on the market for over eight years. Our results show that while the mean deviations were higher than that of the other scanners, the later software version has improved both the mean accuracy and lowered the standard deviation. Interestingly, the Einscan SE lab scanner produced results with a high degree of trueness (15.6 \pm 9.5$)$. However, this was overall trueness to the master STL, and on observational inspection of the triangular meshes, it is evident that the surface detail is lacking. (Figure 6.)

Figure 6. Comparison of Triangular Meshes 


\section{LAB SCANNERS}

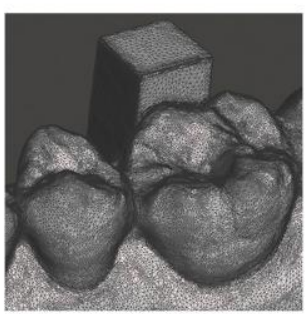

Ineos X5

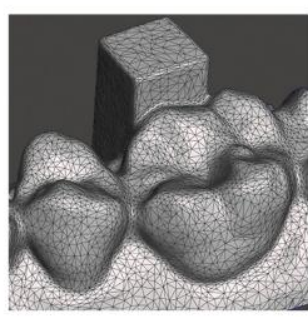

3Shape E2

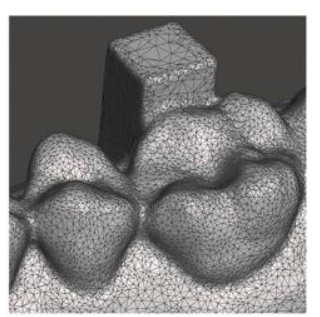

UP3D 300E

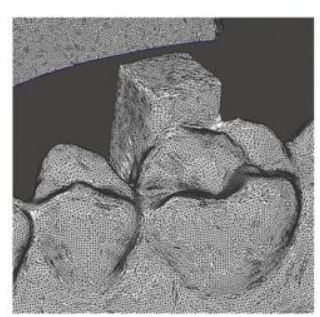

Shining Einscan SE

INTRAORAL SCANNERS

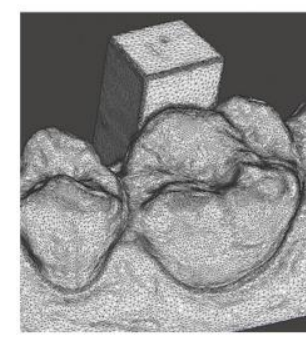

Primescan

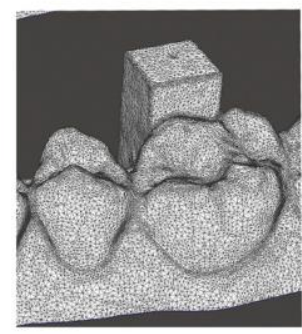

$\operatorname{cs} 3600$

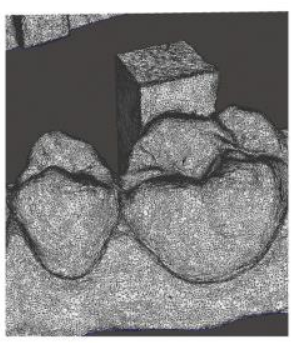

Omnicam 5.1

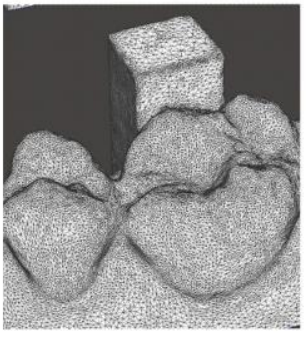

Trios 4

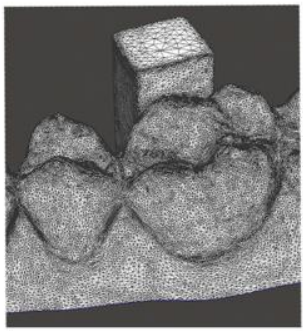

Trios 3

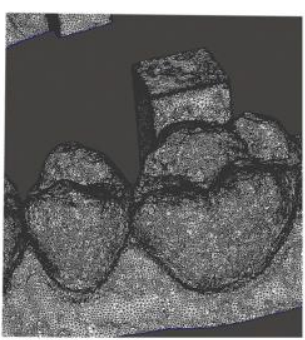

Omnicam 4.6

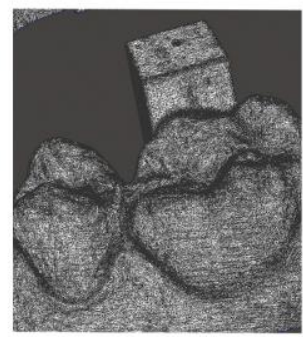

Medit 1500

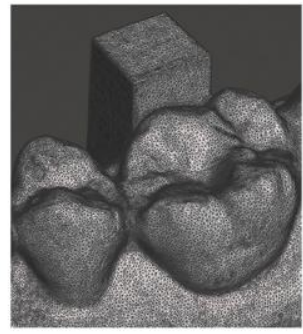

Runyes 3DS

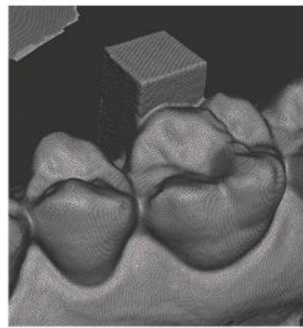

Launca DL206

\section{Discussion}

The null hypothesis was rejected, in that significant differences were found among some of the digital Intra-oral scanners and lab scanners regarding trueness and precision.

With regards to the secondary null hypothesis, that there would be no difference between the lab scanners and intra-oral scanners regarding accuracy and precision, this was partially rejected as one intra-oral scanner, the Primescan, whilst having a statistically significant difference to the Ineos X5 lab scanner, proved the secondary null hypothesis correct as in terms of comparison to the other lab scanners. 
The evolution of intra-oral scanners to lead to one performing at a statistically significant level in comparison to lab scanners is remarkable. Whilst clear differences between the scanners were found, the performance of these scanners can be seen to be exceptional with all lab and intra-oral scanners performing with overall trueness under $60-\mu \mathrm{m}$. The emergence of intra-oral scanners has intended to provide a better experience for the patient and also an easier way of creating a model in a more predictable and repeatable way to alleviate problems/complications encountered in conventional methods/impressions.[1]

As digital intra-oral scanners are becoming more prevalent in practice, it has allowed us to provide same day dentistry in a predictable and efficient way. This has led to the advent of same day dentistry where indirect restorations can be placed in the same visit. There has, however, been a lot of discussion around the accuracy and reproducibility of digital intra-oral scanners versus the conventional analogue techniques - eg digital vs analog impression.[23,24,25] It is generally accepted that the marginal fit of complete coverage restorations constructed using digital scanners show higher accuracy than conventional impressions, but full arch scans are more controversial and technique sensitive and that the scanner being used plays a big part in the overall accuracy and precision of the digital model created.[26,27]

The purpose of this study is to address these issues around precision/trueness and accuracy for a full arch scan. We have studied these parameters for 7 digital intra-oral scanners and 2 lab scanners. This is the most up to date study on the most recent scanners that have been released as of the start of 2021. However, this study did not replicate an actual clinical situation and has several limitations. In most patients, multiple surfaces and materials are scanned, including various restorative materials, dentin, enamel and soft tissues. Inherent anatomy related changes in arch shape on jaw opening mean that this in vitro study is fundamentally limited and in vivo studies using these scanners would be important to further illustrate the differences in accuracy. Further studies should be completed to determine whether these factors may affect full arch accuracy in these current generation scanners.

In the present study, only one clinician performed the scans on the master model to produce the data set for each scanner. This is important as variation in scan strategy can affect the accuracy of stitching which in turn would impact on the significance of the results comparison.[28,29,30]

The terms trueness and precision have been prescribed in ISO 5725-1 to represent the accuracy of the measurement method to evaluate digital intra-oral scanners.[18] Lab scanners are known to be more accurate, as they use lasers or structured light and are not purely optical with a limited field of view such as digital intra-oral scanners and also exhibit less inhibiting factors (For example; lens wetting, reflections from scanned surfaces, movement of the tongue / soft tissues etc) to deal with when scanning,[31] and have therefore been used in this study as benchmark for the accuracy and precision of the scanners.

There are many published studies that compare the accuracy of digital intra-oral scanners $[23,24,25,32,33]$ - they compare different generations of scanners and do not necessarily compare new technology and software updates for the older technology scanners eg the Omnicam with 4.6 software compared to the Omnicam running 5.1 software. Mathematical and software developments of the stitching algorithm[34,35] have improved and this is clear in the results of this study where the later software version combined with more recent computer hardware has resulted in a more accurate data set. It has also been shown that calibration plays a very big part in the accuracy and precision of the scanner,[36] and in the present study all scanners were calibrated immediately prior to the capture of the scans in each data set. 
Looking at the observational comparison of the triangular meshes, it becomes apparent that there are clear differences in the ability of these lab and intra-oral scanners to accurately portray surface features and marginal integrity. In terms of the lab scanners, we can see that as the deviation in trueness increases, so does the lack of detail. However this is not the case for the intra-oral scanners. There is a large variation in the portrayal of occlusal anatomy as well as some degree of difficulty in some of the scanners to efficiently process flatter areas. Whilst it may seem appropriate to look at the total triangle count for the scans, each scanner processes the point clouds differently, converting the point cloud created during scanning to a useable CAD triangle mesh. The more well known brand scanners from Dentsply Sirona, 3Shape and Carestream show obvious variation in the triangular mesh size and density whilst the newer scanners from Medit, Runyes and Launca are very regular in their mesh density. This may be because these scanners have a longer history of research and development and as such the algorithms employed to convert the point clouds recorded into triangular meshes will have had more time to be optimised. One of the most impressive meshes on first observation was the Launca DL206 scan. This scanner has just been released as of the start of 2021 and whilst the trueness is on par with the Runyes and Omnicam scanners, the triangular mesh of this scanner shows an impressive level of detail. However without a full understanding of the manufacturers particular patented methods of algorithmic conversion from point cloud to triangular mesh, this is a potential limitation of comparing the appearance of triangular meshes and total triangle count.

The fast pace changes and developments in modern dentistry within CAD/CAM, digital impression registration and chair-side production are remarkable and likely to quickly become an even greater factor in developing modern dentistry. A central part of the modern digital dentistry office is registering a true and accurate scan of the intra-oral anatomy. The use of digital intra-oral scanners is well established and a number of well tested scanners are available on the market. Needless to say, it is a competitive field for the manufacturers of dental equipment and we can look forward to ongoing improvements. It is widely accepted that the use of a digital intra-oral scanners enhance the patient experience. The in-house workflow gives the clinician opportunities to capture a detailed three dimensional picture of the intra-oral situation, thus enabling same day dentistry and many new opportunities.

An abundance of data indicate that although we can very accurately record the situation and produce reliable digital models of preparations we have limited data of trueness and accuracy across the variety of devices commercially available. Some studies suggest that scanners can replace impressions for dental preparations but it is not clear if they can replace a conventional impression in every situation.[37,38,39]

Several recent studies have shown that digital intra-oral scanners are accurate, but some variations are noted. The older studies suggesting that accuracy of scanners is limited and suggest using scanners for smaller prosthetic situations seem to be based on limited numbers of scanners, and notably older scanners.[40] The present study includes the latest scanners and shows a very different situation as the majority of current scanners, with the latest software, produced results that were accurate to within 30 microns.

\section{Conclusions}

At the time of completing the present study, there have been very few studies comparing the accuracy of the various current intra-oral scanners to assess full arch accuracy.

Our present study aimed to compare the full arch trueness and precision of the leading intra-oral scanners available in 2020 (specifically the Dentsply Sirona Primescan and Omnicam (both 4.6 and 5.1 version), 3Shape Trios 3 and 4, Carestream 3600, Launca DL206, Runyes, and Medit i500) as well as a low-cost lab light scanner (Shining Einscan 
SE) and more mainstream dental lab scanners (Dentsply Sirona Ineos X5, 3Shape E2, and UP3D 300e).

Each scanner took ten scans, and all data sets were compared using Cloudcompare to evaluate the trueness and precision. The study results showed that the Primescan produced a very low amount of overall deviation and recorded the most accurate results, which were statistically similar to all lab scanners except the Ineous X5. The Primescan was followed closely by the Trios 4, Medit i500, CS3600, and Trios 3 as the second most accurate data set of intra-oral scanners with no statistical difference between the overall results of the current range of scanners; Primescan, Trios 3 and 4, i500 and 3600. The results confirmed a statistical difference between these scanners and the previous generation scanner, the Omnicam, and the Runyes and Launca DL206. However, the later generation hardware and software version of the Omnicam did produce more accurate results, and these results of these three scanners were still within an acceptable range for clinical usefulness.

While this and other studies have looked at the accuracy of these scanners, an interesting observational outcome of the present study was examining the close-up anatomical detail shown by the triangular meshes. There is a very clear and noticeable difference in the level of detail shown by the Ineos X5 to the other lab scanners and similarly with the Primescan. The scanners show a variation in their ability to efficiently portray the flat surfaces while also showing higher concentration in triangular mesh around important surface features and angles. The two newer scanners, the Runyes and particularly the Launca DL206, show an impressive level of detail, with the Launca DL206 scanner mesh being evenly rendered with a very dense mesh. This is noticeable in the Launca DL206's STL file size being larger than all other scanners.

This study confirms that all of the intra-oral digital scanners can capture a reliable, reproducible full arch scan in dentate patients. However, the scanning of an edentulous full arch is more challenging and deserves further investigation.

A number of limitations are suggested in our in vitro study, namely the in vivo complications such as saliva, blood, patient interaction, etc. These need to be accounted for and may impact the results in an in vivo patient setting.

Following this study, further research is needed on these scanners in various settings, and the evidence must be confirmed in a clinical setting.

Supplementary Materials: The following are available online at www.mdpi.com/xxx/s1, Figure S1: title, Table S1: title, Video S1: title.

Author Contributions: Author: Adam Nulty; Contributed to conception, design, data acquisition and interpretation, drafted and critically revised the manuscript. The author gave his final approval and agrees to be accountable for all aspects of the work.

Funding: This research received no external funding

Conflicts of Interest: There is no conflict of interest to declare. The author has no financial interests or connections, direct or indirect, that might compromise the perception of the authors as impartial. There is no financial interest that includes commercial or other sources of funding for the author or associated department(s) or organization(s), personal relationships, or direct academic competition.

\section{References}

1. Mörmann WH. The evolution of the CEREC system. J Am Dent Assoc. 2006;137 Suppl:7S-13S.

2. Kim RJY, Park JM, Shim JS. Accuracy of 9 intraoral scanners for complete arch image acquisition: A qualitative and quantitative evaluation. J. Prosthet. Dent. 2018, 120, 895-903.

3. Lee JH, Yun JH, Han JS, Yeo ISL, Yoon HI. Repeatability of Intraoral Scanners for Complete Arch Scan of Partially Edentulous Dentitions: An In vitro Study. J. Clin. Med. 2019, 8, 1187. 
4. Chun JH, Tahk J, Chun YS, Park JM, Kim M. Analysis on the accuracy of intraoral scanners: The effects of mandibular anterior interdental space. Appl. Sci. 2017, 7, 719.

5. Braian M, Wennerberg A. Trueness and precision of 5 intraoral scanners for scanning edentulous and dentate complete arch mandibular casts: A comparative in vitro study. J. Prosthet. Dent. 2019.

6. Medina-Sotomayor P, Pascual-Moscardo A, Camps I. Accuracy of 4 digital scanning systems on prepared teeth digitally isolated from a complete dental arch. J. Prosthet. Dent. 2019, 121, 811-820.

7. Jung S, Park C, Yang HS, Lim HP, Yun KD, Ying Z, Park SW. Comparison of different impression techniques for edentulous jaws using three-dimensional analysis. J. Adv. Prosthodont. 2019, 11, 179-186.

8. Fukazawa S, Odaira C, Kondo H. Investigation of accuracy and reproducibility of abutment position by intraoral scanners. J. Prosthodont. Res. 2017, 61, 450-459.

9. Uhm SH, Kim JH, Jiang HB, Woo CW, Chang M, Kim KN, Bae JM, Oh S. Evaluation of the accuracy and precision of four intraoral scanners with 70\% reduced inlay and four-unit bridge models of international standard. Dent. Mater. J. 2017, 36, 2734.

10. Park GH, Son K, Lee KB. Feasibility of using an intraoral scanner for a complete arch digital scan. J. Prosthet. Dent. 2019, 121, 803-810.

11. Park S, Kang HC, Lee J, Shin J, Shin YG. An enhanced method for reg- istration of dental surfaces partially scanned by a 3D dental laser scanning. Comput Methods Programs Biomed 2015;118:11-22.

12. Mao Z, Park K, Lee K, Li X. Robust surface reconstruction of teeth from raw pointsets. Int J Numer Method Biomed Eng 2014;30: 382-396.

13. Nedelcu RG, Persson AS. Scanning accuracy and precision in 4 intraoral scanners: an in vitro comparison based on 3-dimensional analysis. J Prosthet Dent 2014;112:1461-1471.

14. Fisher B, McDonagh S. Simultaneous registration of multi-view range images with adaptive kernel density estimation. Institute of Mathe- matics and its Applications, 2013:31-62.

15. Zimmerman M, Mehl A, Mörmann WH, Reich S. Intraoral scanning systems - a current overview. Int J Comput Dent 2015;18:101-129.

16. Richert R, Goujat A, Venet L, et al. Intraoral Scanner Technologies: A Review to Make a Successful Impression. J Healthc Eng 2017;2017: 8427595.

17. International Organization for Standardization. Accuracy (trueness and precision) of measurement methods and results e Part 1: General principles and definitions (ISO 5725e1:1994). Berlin: Beuth Verlag GmbH; 1997.

18. Ender A, Mehl A. Accuracy of complete-arch dental impressions: a new method of measuring trueness and precision. J Prosthet Dent 2013;109:121-8

19. International Digital Dental Academy. Available at: www.idda.org

20. Ineos X5 Lab Scanner Information. Available at: https://www.dentsplysirona.com/en/explore/lab/cad-cam-equipment-dental$\underline{\mathrm{lab} / \mathrm{scan} \cdot \mathrm{html}}$

21. Meshlab. (Available at: www.meshlab.net)

22. SPSS 26. (https://developer.ibm.com/predictiveanalytics/2019/04/09/whats-new-in-spss-statistics-26/)

23. Menini M, Setti P, Pera F, Pera P, Pesce P. Accuracy of multi-unit implant impression: traditional techniques versus a digital procedure. Clin Oral Investig. 2018;22(3):1253-1262. doi:10.1007/s00784-017-2217-9

24. Sakornwimon N, Leevailoj C. Clinical marginal fit of zirconia crowns and patients' preferences for impression techniques using intraoral digital scanner versus polyvinyl siloxane material. J Prosthet Dent. 2017;118(3):386-391.

25. Rech-Ortega C, Fernández-Estevan L, Solá-Ruíz MF, Agustín-Panadero R, Labaig-Rueda C. Comparative in vitro study of the accuracy of impression techniques for dental implants: Direct technique with an elastomeric impression material versus intraoral scanner. Med Oral Patol Oral Cir Bucal. 2019;24(1):e89-e95. Published 2019 Jan 1.

26. Amin S, Weber HP, Finkelman M, El Rafie K, Kudara Y, Papaspyridakos P. Digital vs. conventional full-arch implant impressions: a comparative study. Clin Oral Implants Res. 2017;28(11):1360-1367.

27. Patzelt SB, Emmanouilidi A, Stampf S, Strub JR, Att W. Accuracy of full-arch scans using intraoral scanners. Clin Oral Investig. 2014;18(6):1687-1694.

28. Ender A, Mehl A. Influence of scanning strategies on the accuracy of digital intraoral scanning systems. Int J Comput Dent 2013;16:11-21.

29. Lim JH, Park JM, Kim M, Heo SJ, Myung JY. Comparison of digital intraoral scanner reproducibility and image trueness considering repetitive experience. J Prosthet Dent 2018;119:225-232.

30. Nagy ZA, Simon B, Tóth Z, Vág J. Evaluating the efficiency of the Den- tal Teacher system as a digital preclinical teaching tool. Eur J Dent Educ 2018;22:e619-e623.

31. Kang BH, Son K, Lee KB. Accuracy of Five Intraoral Scanners and Two Laboratory Scanners for a Complete Arch: A Comparative In Vitro Study. Appl. Sci. 2020, 10, 74.

32. Mangano F, Gandolfi A, Luongo G, Logozzo S. Intraoral scanners in dentistry: a review of the current literature. BMC Oral Health. 2017;17(1):149. Published 2017 Dec 12.

33. Mangano FG, Hauschild U, Veronesi G, Imburgia M, Mangano C, Admakin O. Trueness and precision of 5 intraoral scanners in the impressions of single and multiple implants: a comparative in vitro study. BMC Oral Health. 2019;19(1):101. Published 2019 Jun 6.

34. Weise T, Wismer T, Leibe B, Van Gool L. Online loop closure for real- time interactive 3D scanning. Computer Vision and Image Under- standing 2011;115:635-648. 
35. Arold O, Yang Z, Ettl S, Häusler G. A new registration method to robustly align a series of sparse 3D data. DGaO-Proceedings 110, 2009:20.

36. Rehmann P, Sichwardt V, Wöstmann B. Intraoral Scanning Systems: Need for Maintenance. Int J Prosthodont. 2017;30(1):27-29.

37. Andriessen FS, Rijkens DR, van der Meer WJ, Wismeijer DW. Applicability and accuracy of an intraoral scanner for scanning multiple implants in edentulous mandibles: a pilot study. The Journal of Prosthetic Dentistry, vol. 111, no. 3, pp. 186-194, 2014.

38. Mangano FG, Veronesi G, Hauschild U, Mijiritsky E, Mangano C. Trueness and precision of four intraoral scanners in oral implantology: a comparative in vitro study. PLoS One, vol. 11, no. 9, article e0163107, 2016.

39. Ng J, Ruse D, Wyatt C. A comparison of the marginal fit of crowns fabricated with digital and conventional methods. The Journal of Prosthetic Dentistry, vol. 112, no. 3, pp. 555-560, 2014.

40. Nedelcu R. Olsson P, Nyström I, Rydén J, Thor A. Accuracy and precision of 3 intraoral scanners and accuracy of conventional impressions: a novel in vivo analysis method. Journal of Dentistry, vol. 69, pp. 110-118, 2018 